\title{
Neighbourhood fruit and vegetable availability and consumption: the role of small food stores in an urban environment
}

\author{
J Nicholas Bodor ${ }^{1}$, Donald Rose ${ }^{1, *}$, Thomas A Farley ${ }^{1}$, Christopher Swalm ${ }^{1}$ and \\ Susanne K Scott ${ }^{2}$ \\ 'Department of Community Health Sciences, School of Public Health and Tropical Medicine, Tulane University, \\ 1440 Canal Street, Suite 2301, New Orleans, LA 701 12, USA: ${ }^{2}$ College of Public Health, Division of \\ Epidemiology, The Ohio State University, Columbus, OH, USA
}

Submitted 15 September 2006: Accepted 26 April 2007: First published online 6 July 2007

\begin{abstract}
Objective: Previous studies on the relationship of dietary intake to the neighbourhood food environment have focused on access to supermarkets, quantified by geographic distance or store concentration measures. However, in-store food availability may also be an important determinant, particularly for urban neighbourhoods with a greater concentration of small food stores. This study synthesises both types of information - store access and in-store availability - to determine their potential relationship to fruit and vegetable consumption.

Design: Residents in four census tracts were surveyed in 2001 about their fruit and vegetable intake. Household distances to food stores in these and surrounding tracts were obtained using geographical information system mapping techniques. In-store fruit and vegetable availability was measured by linear shelf space. Multivariate linear regression models were used to measure the association of these neighbourhood availability measures with consumption.

Setting: Four contiguous census tracts in central-city New Orleans.

Subjects: A random sample of 102 households.

Results: Greater fresh vegetable availability within $100 \mathrm{~m}$ of a residence was a positive predictor of vegetable intake; each additional metre of shelf space was associated with 0.35 servings per day of increased intake. Fresh fruit availability was not associated with intake, although having a small food store within this same distance was a marginal predictor of fruit consumption.

Conclusions: The findings suggest the possible importance of small neighbourhood food stores and their fresh produce availability in affecting fruit and vegetable intake.
\end{abstract}

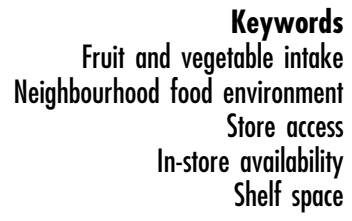

A growing body of research in public health and nutrition has addressed the role of environments in shaping dietary behaviour and health outcomes ${ }^{1-4}$. Studies examining the neighbourhood food environment have focused mainly on access to supermarkets as an influence on consumption. For example, Morland et al. found that with each additional supermarket in a census tract, fruit and vegetable intake increased ${ }^{5}$. Rose and Richards showed that increased supermarket access was a positive predictor of fruit consumption among participants in the US Food Stamp Program ${ }^{6}$, while Laraia et al. found that pregnant women living in closer proximity to a supermarket consumed higher-quality diets ${ }^{7}$.

The 'in-store environment' and its effect on consumption has also been the subject of considerable research, but has been confined almost exclusively to the field of marketing. This literature provides a number of studies that have shown how in-store availability can affect consumers' purchasing behaviours ${ }^{8-10}$. Curhan found that increasing the amount of space dedicated to fresh produce items in a supermarket resulted in higher sales of fresh fruit and vegetable items ${ }^{10}$. Additional papers have found a correlation between the availability of particular foods in the surrounding neighbourhood and the reported consumption of such foods ${ }^{11-13}$.

Underlying the hypothesis that improved access to stores improves consumption of certain products is the assumption that such stores contain these products. Researchers interested in fruit and vegetable consumption have studied access to supermarkets, since these stores 
typically have well-stocked produce departments. Smaller neighbourhood food stores have more limited produce availability and their selection varies considerably between stores ${ }^{14}$. But such stores may play an important role in the consumption patterns of low-income consumers with limited access to transportation and could be particularly important for small fill-in shopping for perishable items, like produce. To further the understanding of the impact of the neighbourhood environment on consumption, in particular the influence of small food stores, the present exploratory study integrates two types of information - access to food stores and in-store availability of specific products - into the same predictive model of consumption.

This research was conducted in 2001 in New Orleans. The study site was selected in an area of the city that is typical of older urban areas throughout the country in which stores are within walking distances of residences. The study focused on the consumption of fruits and vegetables, which is appropriate given their documented importance for health ${ }^{15-19}$ and because of the inadequacy of their consumption, especially among low-income populations $^{20,21}$. In New Orleans, only $19 \%$ of individuals met the US '5-a-day' recommendation. Of 105 metropolitan areas in the country, the New Orleans area ranked 92 nd on this statistic ${ }^{22}$.

\section{Methods}

\section{Study sample}

This study was conducted in June and July of 2001. Four contiguous census tracts were selected in central-city New Orleans, Louisiana. Nearly 6000 people resided in these tracts; $65.2 \%$ of the population was African American and $39.5 \%$ lived below the poverty line ${ }^{23,24}$. These tracts were chosen because they contained a diversity of socio-economic and racial/ethnic groups and exhibited high levels of land-use mix, with small neighbourhood stores intermingled with residences. The relatively close proximity of residences to stores found in these tracts is common to many urban neighbourhoods in the country, and made this geographic area especially conducive to the study of small food stores and their potential impact on consumption. A random sample of household phone numbers was systematically selected from this area. The phone numbers were obtained from Powerfinder, version 1.3 (InfoUSA, Inc., 2001). Telephone interviews were conducted with a respondent from each household, usually the primary shopper of each residence, or if they were not available, another adult of the household. Two hundred and eight households were contacted, of which 111 agreed to be interviewed. Nine of the cases were missing household address information, leaving a final analytic sample of 102 households. All data were collected by graduate-level nutrition and dietetic students.

\section{Fruit and vegetable intake}

Fruit and vegetable intake was determined using an instrument to elicit recall of fruit and vegetable consumption in the previous 24 hours. This instrument was incorporated into the telephone-administered questionnaire and listed a set of commonly consumed fruits (specifically apples, bananas, oranges and grapes) and vegetables (specifically lettuce, dark leafy greens, tomatoes, carrots, green beans and cabbage). Respondents were asked to indicate whether or not each of these specific fruit and vegetable items were consumed during the previous 24 hours and the number of servings they had consumed. A serving was defined as a single fruit or vegetable item or the approximate size of a hand made into a fist. The respondents were also prompted to indicate up to two 'other' fruits and two 'other' vegetables they had consumed that were not one of those listed above. The instrument did not take into account fruits or vegetables from mixed dishes. Our intake variables were determined by summing the number of servings of fruits and the number of servings of vegetables. Fruit and vegetable intakes were examined separately since previous research has found that food access predictors may affect the intake of these foods differently ${ }^{6}$.

\section{Housebold demographics}

Information on the demographic characteristics of the household and car ownership was also collected in the household survey. This included the gender, age and race/ethnicity of the respondent, and the household size and income. Race/ethnicity was categorised into African American, White, Latino, Asian, or other. Since only a small number of Latino and Asian respondents were found in the sample, they were combined into the 'other' category. Respondents identified their annual household income as being in one of seven ranges (e.g. \$0-\$4999, $\$ 5000-\$ 9999$, etc.). A poverty-index ratio (PIR) was calculated by dividing the midpoint of the income range, selected by the respondent, by the US 2001 poverty threshold for the size of their household ${ }^{25}$. Households were divided into three income groups: those in poverty $(\mathrm{PIR}<1)$; those with incomes above the poverty line but still qualifying for some food assistance programmes, like WIC (Special Supplemental Nutrition Program for Women, Infants, and Children) or School Lunch $(1 \leq \mathrm{PIR}<1.85)$; and those with a PIR of 1.85 or above. Respondents were also asked whether anyone in the household received food stamps, participated in the WIC programme, or received some other form of food assistance. In addition, information was collected on whether someone in the household owned a car.

\section{Food store access}

All of the food stores listed for 2001 in the Louisiana Office of Public Health's (OPH) list of food retailers 
within or bordering the study's four census tracts, along with supermarkets that were within $5 \mathrm{~km}$ of the tract borders, were included in our analysis $(n=24)$ of store access. No supermarkets were located within the study tracts. To be comprehensive in our description of store access, it was necessary to include supermarkets beyond the tract borders, since previous research has indicated the importance of supermarkets for consumption ${ }^{5-7,26}$. The completeness of the OPH database was verified by driving around the study neighbourhoods and visually locating all of the food retailers. Stores were categorised into two groups - small food stores and supermarkets, based on codes in the OPH database for annual gross sales. Stores with a code indicating sales greater than $\$ 5000000$ were classified as supermarkets, while stores with sales less than $\$ 1000000$ were classified as small food stores. None of the food retailers in our study area had codes indicating annual sales between $\$ 1000000$ and $\$ 5000000$. All stores and household residences were geocoded using ArcGIS, version 8.3 (ESRI, Inc., 2003) and straight-line distances from each household to each store were calculated.

Previous research on food store access and consumption has used either distance to store ${ }^{6,7}$ or density measures ${ }^{5}$. Our analyses included both types of measures by using the geographical information system (GIS)generated distances to construct two variables describing small food store access: distance to the nearest small food store in kilometres and a dichotomous variable indicating the existence of a small food store within 100 metres of the household residence. This latter access variable can be seen as a measure of small food store density, i.e. the number of stores within a specified radius of the respondent's residence. The distance of 100 metres was selected because it represented the approximate size of a city block. Even though the primary focus of this study was to examine small food store access, similar supermarket access measures were also created considering that prior studies have indicated their importance. Two variables were constructed to represent supermarket access: distance to nearest supermarket in kilometres and a dichotomous variable indicating the existence of a supermarket within 1000 metres of the household. Since supermarkets were located outside the study tracts, their density measure necessitated a larger radius. We used dichotomous expressions for all of the density variables both for simplicity and because most cases took on values of zero or one.

\section{In-store availability}

Store surveys were performed to determine in-store fruit and vegetable availability. Information on linear shelf space devoted to fruits and vegetables and the number of fresh produce varieties available within each store was obtained for 15 small food stores and three supermarkets.
Trained observers used measuring wheels to determine shelf space lengths. This measurement was done separately for fresh, canned and frozen fruits and vegetables. Information on fresh produce varieties was gathered by counting the number of varieties available for individual fruits items (specifically apples, bananas, grapes and oranges) and individual vegetable items (specifically lettuce, dark leafy greens, cabbage, green beans, tomatoes and carrots). Data from the surveyed small food stores were used to impute availability values for one small food store for which we did not have in-store data. The imputed values for this store were calculated by taking the average of the fruit and vegetable availability measurements for all the other small food stores.

\section{Neigbbourbood availability}

The neighbourhood availability measures synthesised information on food store access and in-store availability. These measures were constructed by summing all of the shelf space devoted to fresh fruits or fresh vegetables in all small food stores within $100 \mathrm{~m}$ of the household residence. Thus, one variable reflected availability of fresh fruits within a block distance of a household and the other variable represented fresh vegetable availability within the same distance. Similar neighbourhood availability variables were created for total fruit and total vegetable shelf space, i.e. the sum of fresh, canned and frozen shelf space lengths, and fresh fruit and fresh vegetable varieties within $100 \mathrm{~m}$. These neighbourhood availability measures were an adaptation of the 'cumulative accessibility potential', a GIS modelling concept that measures the magnitude of availability (e.g. amount of shelf space) while accounting for the travel distance to each source ${ }^{27}$. Only small food store fruit and vegetable availability data were used to create these measures. Since the immediate neighbourhood environment around the household was the focus of our study, we did not include shelf space from supermarkets in these availability measures, as the nearest supermarket to any resident was $0.8 \mathrm{~km}$.

\section{Statistical analysis}

Differences in mean fruit and vegetable intake by various demographic, socio-economic and access variables were assessed using $t$-tests for dichotomous variables, with a type I error rate of $\alpha<0.05$. Analysis of variance was used for variables with more than two categories (i.e. age, race/ethnicity and income). Post hoc testing using the least significant difference was used to determine differences in intake with the reference category of these variables (Table 3) when the main effect was significant.

Multivariate linear regression analysis was used to assess the association of consumption with neighbourhood store access and food availability variables, while 
controlling for household demographic factors. Separate equations were estimated for fruits and for vegetables. Because previous research on access and consumption is so limited, the literature gives little guidance concerning which dimensions of access are important. For example, although studies have documented the importance of supermarket density ${ }^{5}$ and distance to the nearest supermarket $^{6,7}$, there is no indication as to whether or not shelf space of all fruits, shelf space of fresh fruits, or the number of different varieties of fresh fruits are important dimensions of neighbourhood availability. Thus, we tested hypotheses concerning each of these dimensions of access and availability in separate, but equivalent, models that controlled for the same set of demographic and socio-economic variables. This set included gender, ethnicity and age of the individual, as well as car ownership, income of the household and food assistance programme participation. Our models on neighbourhood fruit and vegetable availability also controlled for distance to the nearest supermarket. Data management and statistical analyses were performed using SPSS, version 12.0 (SPSS, Inc., 2003).

\section{Results}

The socio-economic characteristics of the study sample are shown in Table 1 . The majority of the respondents were female and over half of the sample was African American. Thirty-one per cent of households had annual incomes below the poverty threshold, and 19\% had someone in their household who received some form of governmental food assistance. Over $70 \%$ of respondents owned a car or had someone in their household who owned one.

Information on fruit and vegetable availability in the neighbourhood food stores is shown in Table 2. Mean fruit and vegetable shelf space was considerably larger for supermarkets $(174 \mathrm{~m})$ than for small food stores $(11 \mathrm{~m})$. This discrepancy was especially apparent for fresh produce items, in which supermarkets had greater amounts of shelf space than small food stores, $121 \mathrm{~m}$ of shelf space vs. $4 \mathrm{~m}$. It was also seen in relative terms; $70 \%$ of fruit and vegetable shelf space was allocated to fresh produce in supermarkets, as opposed to $32 \%$ in small food stores. Supermarkets also offered a considerably larger number of varieties of fresh produce than did small food stores (36 vs. 4).

Mean fruit and vegetable intake by socio-economic characteristics and neighbourhood access measures are shown in Table 3. In most cases, socio-economic characteristics were not related to fruit and vegetable consumption. One exception was for female respondents, who consumed 3.1 servings of vegetables per day, significantly higher than the 2.2 servings consumed by male respondents. Associations of consumption with food
Table 1 Socio-economic characteristics of the study sample $(n=102)$

\begin{tabular}{lcr}
\hline Characteristic & $n$ & $\%$ \\
\hline Gender & & \\
Female & 74 & 73.3 \\
$\quad$ Male & 27 & 26.7 \\
Age (years) & & \\
$16-30$ & 18 & 18.2 \\
$31-50$ & 41 & 41.4 \\
$\geq 51$ & 40 & 40.4 \\
Race/ethnicity & & \\
White & 37 & 37.4 \\
Black & 53 & 53.5 \\
Other & 9 & 9.1 \\
Poverty-index ratio & & \\
$\quad<1.00$ & 26 & 31.0 \\
$1.00-1.84$ & 16 & 19.0 \\
$\geq 1.85$ & 42 & 50.0 \\
Household receives food assistance & & \\
Yes & 19 & 19.0 \\
No & 81 & 81.0 \\
Owns a car & & \\
Yes & 74 & 72.5 \\
No & 28 & 27.5 \\
\hline
\end{tabular}

Table 2 Fruit and vegetable availability in neighbourhood food stores

\begin{tabular}{lcc}
\hline Product & Small food stores $(n=15)$ & Supermarkets $(n=3)$ \\
\hline Mean shelf space in & metres $(S D)$ & \\
Fruits & & \\
$\quad$ Fresh & $1.6(1.9)$ & $64.8(14.4)$ \\
Canned & $1.4(0.8)$ & $8.1(2.8)$ \\
Frozen & $0.0(0.1)$ & $1.8(0.7)$ \\
$\quad$ Total & $3.1(2.4)$ & $74.7(13.8)$ \\
Vegetables & & \\
$\quad$ Fresh & $1.9(1.8)$ & $56.3(5.3)$ \\
Canned & $4.8(2.8)$ & $12.5(17.9)$ \\
Frozen & $1.0(1.1)$ & $99.1(22.8)$ \\
Total & $7.7(4.5)$ & \\
Mean number of fresh varieties $(S D)$ & $15.7(2.5)$ \\
Fruits & $1.9(2.4)$ & $20.3(6.5)$ \\
Vegetables & $2.0(2.1)$ & \\
\hline
\end{tabular}

SD - standard deviation.

assistance and car ownership were marginally significant. For example, respondents whose households received food assistance consumed, on average, 2.8 servings of fruits per day compared with 1.9 for those whose households did not $(P=0.055)$. Those who owned a car consumed, on average, 3.0 servings of vegetables per day, while those who did not consumed 2.3 servings $(P=0.088)$.

Respondents who had a small food store within $100 \mathrm{~m}$ had a significantly higher mean intake of vegetables and a marginally significant higher mean intake of fruits $(P=0.083)$. Having a supermarket within $1000 \mathrm{~m}$ did not significantly affect intake. Respondents with no fresh vegetable shelf space available within a block of their residence had the lowest mean intake of vegetables $(2.4$ servings per day), those who had up to $3 \mathrm{~m}$ of fresh 
Table 3 Mean fruit and vegetable intake by socio-economic characteristics, food store access and neighbourhood availability

\begin{tabular}{|c|c|c|}
\hline \multirow{2}{*}{$\begin{array}{l}\text { Socio-economic characteristic } \\
\text { or access/availability measure }\end{array}$} & \multicolumn{2}{|c|}{$\begin{array}{l}\text { Mean consumption in } \\
\text { servings per day (SD) }\end{array}$} \\
\hline & Fruits & Vegetables \\
\hline \multicolumn{3}{|l|}{ Gender } \\
\hline Female & $2.1(1.9)$ & $3.1(2.1)$ \\
\hline Male & $1.8(1.6)$ & $2.2(1.7)^{\star \star}$ \\
\hline \multicolumn{3}{|l|}{ Age (years)† } \\
\hline $16-30$ & $1.4(1.4)$ & $2.7(1.8)$ \\
\hline $31-50$ & $2.4(2.1)$ & $2.8(1.8)$ \\
\hline$\geq 51$ & $2.1(1.5)$ & $3.0(2.3)$ \\
\hline \multicolumn{3}{|l|}{ Race/ethnicity† } \\
\hline White & $1.9(1.6)$ & $2.9(2.3)$ \\
\hline Black & $2.2(2.0)$ & $2.8(1.9)$ \\
\hline Other & $2.0(1.6)$ & $3.0(1.8)$ \\
\hline \multicolumn{3}{|l|}{ Poverty-index ratiot } \\
\hline$<1.00$ & $2.5(2.1)$ & $2.5(1.4)$ \\
\hline $1.00-1.84$ & $2.5(2.1)$ & $2.6(1.7)$ \\
\hline$\geq 1.85$ & $1.9(1.6)$ & $3.2(2.3)$ \\
\hline \multicolumn{3}{|l|}{ Receives food assistance } \\
\hline No & $1.9(1.7)$ & $2.8(2.0)$ \\
\hline Yes & $2.8(2.1)^{\star}$ & $3.2(2.1)$ \\
\hline \multicolumn{3}{|l|}{ Owns a car } \\
\hline No & $2.0(2.2)$ & $2.3(1.5)$ \\
\hline Yes & $2.1(1.6)$ & $3.0(2.1)^{\star}$ \\
\hline \multicolumn{3}{|l|}{ Small food store within $100 \mathrm{~m}$} \\
\hline No & $1.8(1.4)$ & $2.4(1.6)$ \\
\hline Yes & $2.4(2.1)^{*}$ & $3.3(2.3)^{\star *}$ \\
\hline \multicolumn{3}{|l|}{ Supermarket within $1000 \mathrm{~m}$} \\
\hline No & $2.1(1.9)$ & $2.9(2.1)$ \\
\hline Yes & $2.0(1.4)$ & $2.5(1.5)$ \\
\hline \multicolumn{3}{|l|}{ Fresh fruit shelf space within } \\
\hline \multicolumn{3}{|l|}{$100 \mathrm{mt}$} \\
\hline None & $2.0(1.7)$ & - \\
\hline $0-3 \mathrm{~m}$ & $1.8(1.3)$ & - \\
\hline$>3 m$ & $2.3(2.2)$ & - \\
\hline \multicolumn{3}{|l|}{$\begin{array}{l}\text { Fresh vegetable shelf space } \\
\text { within } 100 \mathrm{mt}\end{array}$} \\
\hline None & - & $2.4(1.6)$ \\
\hline $0-3 \mathrm{~m}$ & - & $3.3(2.4)^{\star *}$ \\
\hline$>3 m$ & - & $4.5(2.4)^{\star \star}$ \\
\hline
\end{tabular}

SD - standard deviation.

${ }^{\star} P<0.10 ;{ }^{* \star} P<0.05$.

$\dagger$ The first category is the reference group.

vegetable shelf space within a block had a higher intake (3.3 servings), while those who had greater than $3 \mathrm{~m}$ of fresh vegetable shelf space within a block had the highest intake (4.5 servings). A similar dose-response relationship was not seen for fruits.

Multivariate estimates of consumption were made using separate linear regression models for fruits and vegetables and for each of our neighbourhood access measures (Table 4). All of the models controlled for the basic set of household variables. Distance to the nearest small food store or distance to the nearest supermarket was not associated with fruit or vegetable consumption. Our density measure of small food store access, i.e. having a small food store within $100 \mathrm{~m}$, was a marginally significant positive predictor of fruit consumption ( $P=0.090)$; but none of the measures of neighbourhood fruit availability - i.e. those that considered the amount of fruit shelf space, or the number of varieties near the residence - were significant predictors of fruit intake. Conversely, the amount of fresh vegetable shelf space near the residence was a significant positive predictor of vegetable intake; each extra metre of shelf space was associated with an additional intake of 0.35 servings per day. Other measures of neighbourhood vegetable availability, including total vegetable shelf space and number of fresh vegetable varieties, were positive marginally significant predictors of intake.

\section{Discussion}

The main objective in this paper was to explore the relationship between neighbourhood food availability and consumption through the use of more refined measures of availability, specifically measures that combine information on both store access and in-store contents. Our study investigated the immediate neighbourhood of households in central-city New Orleans, surveying fruit and vegetable availability within $100 \mathrm{~m}$, or about one city block, of their residences. Our analysis shows a positive association of neighbourhood vegetable availability, measured in linear shelf space, with reported vegetable intake. A positive association was not seen for fruit shelf space with fruit intake, although access to a small food store within $100 \mathrm{~m}$ of the residence was marginally associated with an increased fruit intake.

Interestingly, no association was found between intake and access to supermarkets, which differs with prior research in this area ${ }^{5-7}$. The null finding may be related to the specific context of this study. Although there was not a supermarket located within any of the four census tracts studied here, supermarkets were not far away. Moreover, there was little variability in the distance to the nearest supermarket. The average distance that each household needed to travel to reach their closest supermarket was $1.3 \mathrm{~km}$, while the furthest anyone had to travel was $1.7 \mathrm{~km}$. Even though over a quarter of respondents did not own a car, it is possible that most households were able to get to a supermarket for large food shopping trips and then relied on their neighbourhood small food stores for 'fill-in' shopping trips. Prior research has found that a significant proportion of low-income households who report supermarkets as their main source for food also shop at smaller neighbourhood stores ${ }^{26}$. Among our study participants, the nearness of a small food store and the availability of fresh vegetables in these stores may have been important factors when they needed to replenish smaller amounts of perishable foods between their opportunities to go to a supermarket.

Although the amount of fresh vegetable shelf space within a short distance of the household's residence was important in predicting vegetable intake, a similar result was not found for fruits. There are a number of possible explanations for this finding. There may have been less 
Table 4 Regression models results on relationship of food store access and neighbourhood availability to fruit and vegetable consumption

\begin{tabular}{|c|c|c|c|c|c|c|}
\hline \multirow[b]{2}{*}{ Access/availability measure } & \multicolumn{3}{|c|}{ Consumption of fruits (servings per day) } & \multicolumn{3}{|c|}{ Consumption of vegetables (servings per day) } \\
\hline & $\beta$ & SEM & $P$-value & $\beta$ & SEM & $P$-value \\
\hline \multicolumn{7}{|l|}{ Food store accesst } \\
\hline Distance to nearest small food storeł & -4.551 & 3.532 & 0.201 & -3.187 & 3.938 & 0.420 \\
\hline Distance to nearest supermarket $\ddagger$ & 0.445 & 0.955 & 0.642 & -0.094 & 1.060 & 0.930 \\
\hline Has small food store within $100 \mathrm{~m}$ & 0.632 & 0.369 & 0.090 & 0.515 & 0.412 & 0.214 \\
\hline Has supermarket within $1000 \mathrm{~m}$ & -0.123 & 0.518 & 0.813 & -0.075 & 0.575 & 0.897 \\
\hline \multicolumn{7}{|l|}{ Neighbourhood availability§ } \\
\hline Fresh fruit shelf space in $100 \mathrm{~m}$ & 0.089 & 0.113 & 0.434 & - & - & - \\
\hline Total fruit shelf space in $100 \mathrm{~m}$ & 0.088 & 0.073 & 0.232 & - & - & - \\
\hline Fresh fruit varieties in $100 \mathrm{~m}$ & 0.070 & 0.085 & 0.413 & - & - & - \\
\hline Fresh vegetable shelf space in $100 \mathrm{~m}$ & - & - & - & 0.351 & 0.155 & 0.025 \\
\hline Total vegetable shelf space in $100 \mathrm{~m}$ & - & - & - & 0.088 & 0.048 & 0.072 \\
\hline Fresh vegetable varieties in $100 \mathrm{~m}$ & - & - & - & 0.232 & 0.119 & 0.055 \\
\hline
\end{tabular}

$\beta$ - regression coefficient; SEM - standard error of the mean.

t Each measure of food store access was the independent variable in a separate linear regression model that also controlled for gender, ethnicity, age, income, food assistance participation and car ownership of the respondent. Dependent variables were total fruit and vegetable consumption in the previous 24 hours. ¥ The variables distance to nearest small food store and distance to nearest supermarket are both in $\mathrm{km}$.

$\S$ Each measure of neighbourhood availability was the independent variable in a separate linear regression model that had all of the same control variables as above as well as distance to nearest supermarket. The neighbourhood availability measures reflect only the in-store contents of small food stores since no supermarkets were within $100 \mathrm{~m}$ of the households. Dependent variables were total fruit and vegetable consumption in the previous 24 hours.

variability among small food stores in the amount of shelf space dedicated to fruits, the number of fruit varieties, and/or the quality of the fruit produce as compared with vegetables. Another possibility is that residents relied on supermarkets, rather than small food stores, for the purchasing of fruits, for reasons of quality and/or price. Thus the neighbourhood fruit availability measures would not be significant predictors of intake, since no supermarket was located in the immediate neighbourhood of the study households. Finally, there could be less variability in apparent fruit intake than vegetable intake, either because of the actual behaviour of respondents or because of this study's fruit and vegetable survey instrument.

This indicates one possible limitation of our analysis. Overall, $56 \%$ of the sample ate two or more fruits and $54 \%$ ate three or more vegetables per day, which are higher than average in the USA and considerably higher than the averages for poor Americans. Although it is possible that within this small sample the respondents actually had higher-than-average intakes of fruits and vegetables, it is also possible that the design of the fruit and vegetable survey instrument caused inflated intake results. If our instrument caused differential reporting by a third variable related to access, one might also be concerned about bias in our analytical results on the relationship of access and intake. For example, one might posit that higher income or higher educated respondents might overstate consumption in order to provide more 'socially desirable' answers to our fruit and vegetable questions. If these groups also had better access, the relationship between access and intake would have been biased upwards. However, the specific area for our neighbourhood study was very mixed, both socio-economically and racially. We tested and found no significant differences in access or availability by household income or race/ethnicity, thus making it unlikely that our instrument contributed to this type of bias in the relationship between intake and access.

A second limitation of this study is the response rate. Despite attempts to encourage respondent participation by explaining clearly in the survey script that all responses would remain confidential, about half of households chose not to participate. In comparing characteristics of our study sample with data from the 2000 Census of the same tracts, we found that the percentage of African Americans was somewhat lower in our sample (53.5\%) than in the Census data $(65.2 \%)$. The same was true for poverty rates $(31.0 \%$ vs. $39.5 \%)$. As with many surveys, response rates were lower among the poor, which indicates that results should be interpreted with caution ${ }^{28}$.

Another limitation is that data were collected from a small sample confined to a single geographic section of New Orleans. Most households experienced relatively similar exposure to food stores, particularly supermarkets. Future research in this field would benefit from a larger sample and observations on a wider geographic area with more diverse micro-environments. Additionally, respondents were not asked about their level of education and the in-store observations did not obtain information on whether food stores participated in government food assistance programmes. Continuing research in this area would benefit from data collected on these variables.

Finally, because of the cross-sectional nature of our study, causality between the association of neighbour- 
hood availability and intake cannot be inferred. Research based on a longitudinal design, or on a 'natural experiment', could yield more conclusive results. For example, Wrigley et al. used a longitudinal design in the UK to investigate the emergence of a new supermarket in a former 'food desert' and found there to be significant increases in fruit and vegetable consumption ${ }^{29,30}$. A similar design could be used to investigate the effects of increased fruit and vegetable access through the adding of more fresh produce shelf space in local food stores. Creating incentives for small storeowners to stock more fresh produce may help achieve this.

While much of the prior literature has focused on access to supermarkets and its potential influence on dietary intake, this study suggests that access to urban small food stores and their in-store availability of foods may also play a role in affecting diet, in particular vegetable intake. The potential benefits of greater local fruit and vegetable availability may be especially pronounced for poor households without private transportation, who may have a greater reliance on nearby small food stores. Despite these suggestive findings, our study was exploratory in nature; future studies involving a larger sample and covering a wider geographic area are needed. Neighbourhood availability measures similar to the ones developed for this study could be used in such future research. Additionally, research on policies to promote greater fresh produce availability in small food stores could further our understanding of how neighbourhood availability affects fruit and vegetable consumption among urban residents.

\section{Acknowledgements}

Sources of funding: This research was supported in part by a grant from the National Research Initiative of the US Department of Agriculture.

Conflict of interest declaration: There is no conflict of interest to declare.

Authorship responsibilities: The study was conceptualised and designed jointly by J.N.B., D.R. and T.A.F. Data collection was supervised by T.A.F. and S.K.S. C.S. conducted the geographical information system mapping. J.N.B. and D.R. conducted the data analysis. J.N.B. and D.R. led the write-up of the paper with all authors contributing.

Acknowledgements: We thank Stephanie Tortu and Jodi Zighelboim for their help in the development of the survey instrument.

\section{References}

1 Hill JO, Peters JC. Environmental contributions to the obesity epidemic. Science 1998; 280: 1371-4.
2 Diez-Roux AV, Nieto FJ, Caulfield L, Tyroler HA, Watson RL, Szklo M. Neighborhood differences in diet: the Atherosclerosis Risk in Communities Study. Journal of Epidemiology and Community Health 1999; 53: 55-63.

3 French SA, Story M, Jeffery RW. Environmental influences on eating and physical activity. Annual Review of Public Health 2001; 22: 309-35.

4 Diez-Roux AV, Merkin SS, Arnett D, Chambless L, Massing $\mathrm{M}$, Nieto FJ, et al. Neighborhood of residence and incidence of coronary heart disease. New England Journal of Medicine 2001; 345: 99-106.

5 Morland K, Wing S, Diez Roux A. The contextual effect of the local food environment on residents' diets: the Atherosclerosis Risk in Communities Study. American Journal of Public Health 2002; 92 : 1761-7.

6 Rose D, Richards R. Food store access and household fruit and vegetable use among participants in the US Food Stamp Program. Public Health Nutrition 2004; 7: 1081-8.

7 Laraia BA, Siega-Riz AM, Kaufman JS, Jones SJ. Proximity of supermarkets is positively associated with diet quality index for pregnancy. Preventive Medicine 2004; 39: 869-75.

8 Wilkinson JB, Mason JB, Paksoy CH. Assessing the impact of short-term supermarket strategy variables. Journal of Marketing Research 1982; 16: 72-86.

9 Curhan RC. The relationship between shelf space and unit sales in supermarkets. Journal of Marketing Research 1972; 9: 406-12.

10 Curhan RC. The effects of merchandising and temporary promotional activities on the sales of fresh fruits and vegetables in supermarkets. Journal of Marketing Research 1974; 11: 286-94.

11 Cheadle A, Psaty BM, Curry S, Wagner E, Diehr P, Koepsell $\mathrm{T}$, et al. Community-level comparisons between the grocery store environment and individual practices. Preventive Medicine 1991; 20: 250-61.

12 Cheadle A, Psaty BM, Curry S, Wagner E, Diehr P, Koepsell $\mathrm{T}$, et al. Can measures of the grocery store environment be used to track community-level dietary changes? Preventive Medicine 1993; 22: 361-72.

13 Edmonds J, Baranowski T, Baronowski J, Cullen KW, Myres D. Ecological and socioeconomic correlates of fruit, juice, and vegetable consumption among African American boys. Preventive Medicine 2001; 32: 476-81.

14 Morris PM, Neuhauser L, Campbell C. Food security in rural America: a study of availability and cost of food. Journal of Nutrition Education 1992; 24: 52S-8S.

15 Ness AR, Powles JW. Fruit and vegetables and cardiovascular disease: a review. International Journal of Epidemiology 1997; 26: 1-13.

16 Van Duyn MA, Pivonka E. Overview of the health benefits of fruit and vegetable consumption for the dietetics professional: selected literature. Journal of the American Dietetic Association 2000; 100: 1511-21.

17 Key TJ, Schatzkin A, Willett WC, Allen NE, Spencer EA, Travis RC. Diet, nutrition, and the prevention of cancer. Public Health Nutrition 2004; 7: 187-200.

18 Hung HC, Joshipura KJ, Jiang R, Hu FB, Hunter D, SmithWarner SA, et al. Fruit and vegetable intake and risk of major chronic disease. Journal of the National Cancer Institute 2004; 96: 1577-84.

19 Steffen LM, Kroenke CH, Yu X, Pereira MA, Slattery ML, Van Horn L, et al. Associations of plant food, dairy product, and meat intakes with $15-y$ incidence of elevated blood pressure in young black and white adults: the Coronary Artery Risk Development in Young Adults (CARDIA) study. American Journal of Clinical Nutrition 2005; 82: 1169-77.

20 US Department of Health and Human Services (DHHS). Healthy People 2010. Washington, DC: DHHS, 2000. 
21 Serdula MK, Gillespie C, Kettel-Khan L, Farris R, Seymour J, Denny C. Trends in fruit and vegetable consumption among adults in the United States: behavioral risk factor surveillance system, 1994-2000. American Journal of Public Health 2004; 94: 1014-18.

22 Centers for Disease Control and Prevention. SMART: Selected Metropolitan/Micropolitan Area Risk Trends [online], 2003. Available at http://apps.nccd.cdc.gov/brfsssmart. Accessed June 2005.

23 US Census Bureau. Census 2000 Summary File 1 (SF 1) 100-Percent Data [online], 2000. Available at http://factfinder. census.gov/servlet/DownloadDatasetServlet?_lang=en. Accessed July 2006.

24 US Census Bureau. Census 2000 Summary File 3 (SF 3)Sample Data [online], 2000. Available at http://factfinder. census.gov/servlet/DownloadDatasetServlet?_lang=en. Accessed July 2006.

25 US Census Bureau. Poverty Thresholds by Size of Family and Number of Related Children Under 18 Years [online],
2001. Available at http://www.census.gov/hhes/poverty/ threshld/thresh01.html. Accessed January 2005.

26 Ohls JC, Ponza M, Moreno L, Zambrowski A, Cohen R. Food Stamp Participants' Access to Food Retailers. Alexandria, VA: Office of Analysis and Evaluation, US Department of Agriculture, Food and Nutrition Service, 1999.

27 Geertman SCM, Van Eck JRR. GIS and models of accessibility potential: an application in planning. International Journal of Geographical Information Systems 1995; 9: 67-80.

28 Marcus AC, Crane LA. Telephone surveys in public health research. Medical Care 1986; 24: 97-112.

29 Wrigley N, Warm D, Margetts B, Whelan A. Assessing the impact of improved retail access on diet in a 'food desert': a preliminary report. Urban Studies 2002; 39: 2061-82.

30 Wrigley N, Warm D, Margetts B. Deprivation, diet, and food retail access: findings from the Leeds 'food-deserts' study. Environment and Planning A 2003; 35: 151-88. 